\title{
CRESCIMENTO DA PARTE AÉREA DE MUDAS DE COUVE-FLOR PRODUZIDAS EM DIFERENTES SUBSTRATOS EM SISTEMA AGROECOLÓGICO
}

\author{
Julio Cesar Gradice Saluci ${ }^{1}$ \\ Mário Euclides Pechara da Costa Jaeggi² \\ Maxwel Rodrigues Nascimento ${ }^{3}$ \\ Diego Rogério Ferraz ${ }^{4}$ \\ Alex Justino Zacarias ${ }^{5}$ \\ Israel Martins Pereira ${ }^{6}$ \\ Rebyson Bissaco Guidinelli ${ }^{7}$ \\ Rogério Range Rodrigues ${ }^{8}$ \\ Samuel Ferreira da Silva ${ }^{9}$ \\ Wallace Luís de Lima ${ }^{10}$
}

Resumo: A agricultura exerce grande expressividade no desenvolvimento social, político e econômico do Brasil. Contudo existe constate crescimento na procura e exigência por alimentos mais saudáveis, que podem ser produzidos com técnicas da agroecologia. Objetivou-se com este trabalho avaliar diferentes substratos na produção de mudas de couve-flor. O experimento foi em DIC, no esquema fatorial (4x4) avaliando 7 plantas em cada tratamento na fase final de mudas. Os resultados encontrados para a parte aérea, demostraram desenvolvimento satisfatório para a cultura nos substratos orgânicos, em relação ao comercial, sendo que foi observado superioridade das variáveis quando utilizou-se o vermicomposto como substrato, independente das concentrações usadas, entretanto não houve diferença entre as concentrações usadas para esse substrato. Os substratos orgânicos proporcionaram boa produção. Dentre estes substratos destacou-se o vermicomposto.

Palavras-chave: Biometria; Composto orgânico; Cultivo sustentável.

\footnotetext{
${ }^{1}$ Tecnologia em Cafeicultura/Instituto Federal do Espírito Santo, Brasil. E-mail: juliosaluci@gmail.com.

2 Produção Vegetal/Universidade Federal Norte Fluminense, Brasil. E-mail: mariopechara@hotmail.com.

3 Produção Vegetal/Universidade Federal Norte Fluminense, Brasil. E-mail: maxwel.m88@gmail.com.

${ }^{4}$ Agroecologia/Instituto Federal do Espirito Santo, Brasil. E-mail: diegofvalim@hotmail.com.

5 Tecnologia em Cafeicultura/Instituto Federal do Espírito Santo, Brasil. E-mail: alexjustino12@gmail.com.

6 Tecnologia em Cafeicultura/Instituto Federal do Espírito Santo, Brasil. E-mail: israelmartins80@gmail.com.

7 Tecnologia em Cafeicultura/Instituto Federal do Espírito Santo, Brasil. E-mail: rebysonguidinelle@gmail.com.

8 Produção Vegetal/Universidade Federal de Lavras, Brasil. E-mail: rogeriorr7@hotmail.com.

${ }^{9}$ Produção Vegetal/Universidade Federal do Espírito Santo, Brasil. E-mail: samuelfd.silva@yahoo.com.br.

10 Instituto Federal do Espírito Santo, Brasil. E-mail: wallace@ifes.edu.br.
} 